\title{
The Preparation and Properties of Nitrile Rubber Filled with Different Kinds of Zinc Oxide
}

\author{
Liming Tang ${ }^{1,2, a}$, Shijie Wang ${ }^{1, b}$, Xiaoren Lv ${ }^{1, c}$, Enqiu $\mathrm{He}^{1}$ \\ ${ }^{1}$ School of Mechanical Engineering, Shenyang University of Technology, Shenyang, Liaoning, \\ 110870, China. \\ ${ }^{2}$ Shenyang University of Chemical Technology, Shenyang, Liaoning, 110142, China. \\ ayjsliming@sina.com, bwang_shijie@263.net, 'xrlvsut@126.com
}

Keywords: nano-ZnO; conventional ZnO; nitrile rubber; preparation and property.

\begin{abstract}
The vulcanizing properties, physical performances, and wear behaviors of nitrile rubber (NBR) filled with different kinds of Zinc Oxide $(\mathrm{ZnO})$ were studied in this article. Based on samples preparation, this study provides the vulcanizing properties, physical performances and mechanical properties on NBR filled with different kinds of ZnO. This experimental results indicate that, compared with NBR filled with conventional $\mathrm{ZnO}$, the tensile strength, tensile stress at $100 \%$, and tensile stress at $300 \%$ of NBR filled with nano-ZnO are greater. The maximum torque of NBR filled with nano-ZnO is higher than that of NBR filled with conventional $\mathrm{ZnO}$. The scorch time and optimum cure time of NBR filled with nano-ZnO are shortened. The NBR filled with nano-ZnO exhibits the more outstanding wear resistance.
\end{abstract}

\section{Introduction}

Nitrile rubber owns superior oil resistance in all-purpose rubber. It is used in oil resistant rubber slab, fuel tank, oil seal, and stator rubber of screw pump, and so on [1-2]. The same as other non self-reinforcing synthetic rubber, in order to improve the character of service, all kinds of ingredients are added into the nitrile rubber [3-4]. The $\mathrm{ZnO}$ is important compounding agent in rubber industry. It is used as vulcanizing activator in sulfur vulcanizing system. It not only activates the whole vulcanizing system but also improves the property of heat aging resistance [5]. Nano-ZnO and conventional $\mathrm{ZnO}$ own the same chemical composition, but nano-ZnO belongs to nanometer material, which exerts many fantastic characters, e.g. the surface effect, small dimension effect, quantum size effect and macroscopic quantum tunnel effect [6-7]. So, the NBR filled with nano-ZnO, its integrated performance is enhanced significantly. The vulcanizing properties, physical performances, and wear behaviors of NBR filled with different kinds of $\mathrm{ZnO}$ were studied in this article. It is the basic work for further research.

\section{Experimental}

The composition and mass fraction of NBR were listed as follow: N41 100, sulfuration agent 5, stearic 1, ZnO 5 (varieties), carbon black (N330) 60. anti-aging agent 1, and softener 2. Accelerating agents were DM, TMTD, and MgO. The mass fraction was 2.5, 0.25, and 0.15, respectively. The above chemical material of samples could be purchased in the market. The rubber samples were produced by the process of mixing and plate vulcanizing. NBR was vulcanized with the pressure of $10 \mathrm{MPa}$ and the temperature of $150^{\circ} \mathrm{C}$ for tc $90+5 \mathrm{~min}$.

The samples were mixed at room temperature using a two-roll mill. Vulcanizing properties were measured by the no rotor rheometer. The Shore Hardness of samples was measured by Shore durometer with the accuracy of 0.1 and else physical performances were obtained by tension tester. The tribological behavior of samples was measured at room temperature using a abrasive wear tester. During the test, the ring made by $40 \mathrm{Cr}$ steel was rotated on the rubber block under the load of $100 \mathrm{~N}$ for $600 \mathrm{~s}$ and its rotate speed was $200 \mathrm{r} \cdot \mathrm{min}^{-1}$. The weight of samples before and after wear test was 
measured using the electrical balance with the accuracy of $0.1 \mathrm{mg}$. The steady frictional coefficient was collected when the wear condition was stable.

\section{Results and discussion}

The vulcanizing properties of $\mathrm{NBR}$ filled with different kinds of $\mathrm{ZnO}$. The vulcanizing properties of NBR filled with different kinds of ZnO are shown in Table 1. Compared with the NBR filled with conventional $\mathrm{ZnO}$, the maximum torque of NBR filled with nano-ZnO is enhanced by $19 \%$, and the scorch time and optimum cure time is shortened by $13 \%$ and $23 \%$, respectively. On account of surface effect of nano-particle, nano-ZnO owns excellent activity, which is the reason that the scorch time and optimum cure time are shortened.

Table 1 Vulcanizing properties of NBR filled with different kinds of $\mathrm{ZnO}$

\begin{tabular}{lll}
\hline vulcanization parameters & NBR containing nano-ZnO & $\begin{array}{l}\text { NBR containing conventional } \\
\text { ZnO }\end{array}$ \\
\hline MH[dN-m] & 23.76 & 19.99 \\
ML[dN-m] & 1.41 & 2.47 \\
tc10[min] & $2: 12$ & $2: 29$ \\
tc90[min] & $5: 05$ & $6: 16$ \\
\hline
\end{tabular}

The physical performances of NBR filled with different kinds of ZnO. The physical performances of NBR filled with different kinds of $\mathrm{ZnO}$ can be found in Table 2. Compared with the NBR containing conventional $\mathrm{ZnO}$, the tensile strength of $\mathrm{NBR}$ containing nano-ZnO is enhanced by $9.6 \%$. The tensile stress at $100 \%$ and tensile stress at $300 \%$ of NBR containing nano-ZnO is enhanced by $47 \%$ and $30 \%$, respectively. The improvement of physical performances on NBR containing nano-ZnO could result from increase of crosslinking density. Because of nanometer effect of nano-ZnO, it results in the increase of crosslink junction per unit volume, namely the increase of crosslinking density. The Shore Hardness of NBR containing nano-ZnO and NBR containing conventional $\mathrm{ZnO}$ is 72 and 66, respectively.

Table 2 Physical performances of NBR filled with different kinds of ZnO

\begin{tabular}{lll}
\hline physical performances & NBR containing nano-ZnO & $\begin{array}{l}\text { NBR containing conventional } \\
\text { ZnO }\end{array}$ \\
\hline tensile strength[Mpa] & 20.88227 & 19.06165 \\
tensile stress at $100 \%[\mathrm{Mpa}]$ & 3.68202 & 2.49958 \\
tensile stress at $300 \%[\mathrm{Mpa}]$ & 15.27015 & 11.77681 \\
elongation at break $[\%]$ & 399.52153 & 461.13006 \\
shore A hardness & 72 & 66 \\
\hline
\end{tabular}

Tribological behavior of NBR filled with different kinds of ZnO. Fig.1 shows the curve of frictional coefficient with time on NBR containing different kinds of $\mathrm{ZnO}$ under dry sliding. It can be seen from Fig. 1 that the frictional coefficient is basically steady with time. So, the wear mechanism should be single [8-9].

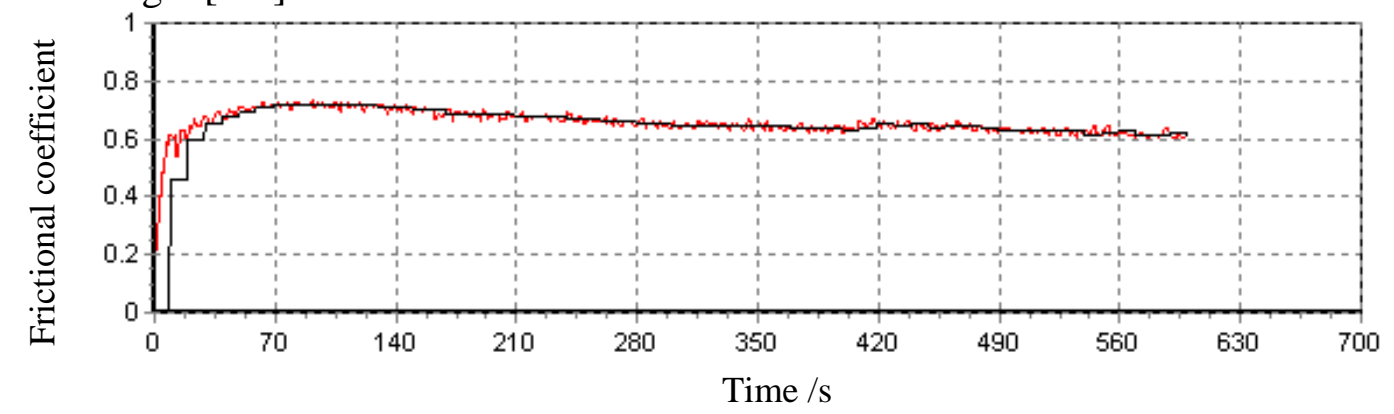

(a) NBR containing conventional ZnO 


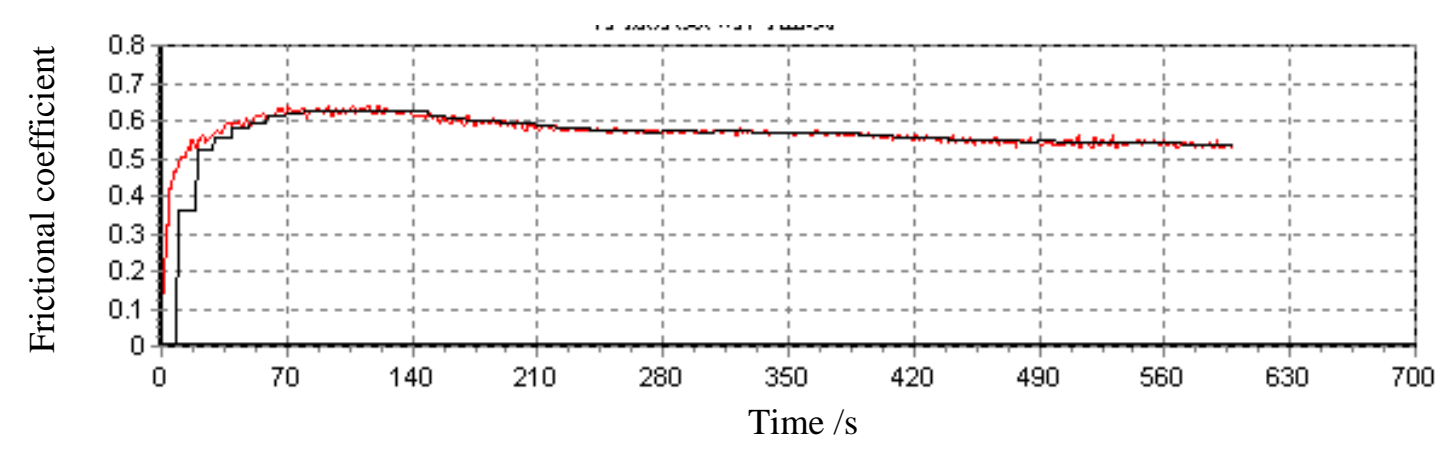

(b) NBR containing nano-ZnO

Fig.1 Curve of frictional coefficient with time on NBR containing different kinds of ZnO under dry sliding

Table 3 shows the stable value of frictional coefficient on both samples. It can be seen from Table 3 that the stable value of NBR containing nano-ZnO is less than that of NBR containing conventional $\mathrm{ZnO}$. This phenomenon should be attributed to the higher hardness of NBR containing nano-ZnO, which results in decrease of real contact area between the steel pair and rubber block [10-13]. So, the force of friction between frictional pair would be reduced, and the frictional coefficient would be reduced, too.

Table 3 Stable value of frictional coefficient of NBR containing different kinds of ZnO under dry sliding

\begin{tabular}{ll}
\hline sample & frictional coefficient \\
\hline NBR containing conventional & 0.66 \\
ZnO & \\
NBR containing nano-ZnO & 0.57 \\
\hline
\end{tabular}

It can be seen from Fig.2 that the wear loss is lesser on NBR containing nano-ZnO than that of NBR containing conventional ZnO. From the point of view of physical chemistry, if the crosslink density of rubber sample is small, then the wear loss of rubber sample will be high. This would be related to low density crosslinking can be easy to be broken by mechanical stress during friction process [14]. Because NBR containing nano-ZnO possesses higher crosslink density and the number of effective molecular chain bearing mechanical stress is more than that of NBR containing conventional $\mathrm{ZnO}$. So, NBR containing nano-ZnO exhibits the more outstanding wear resistance.

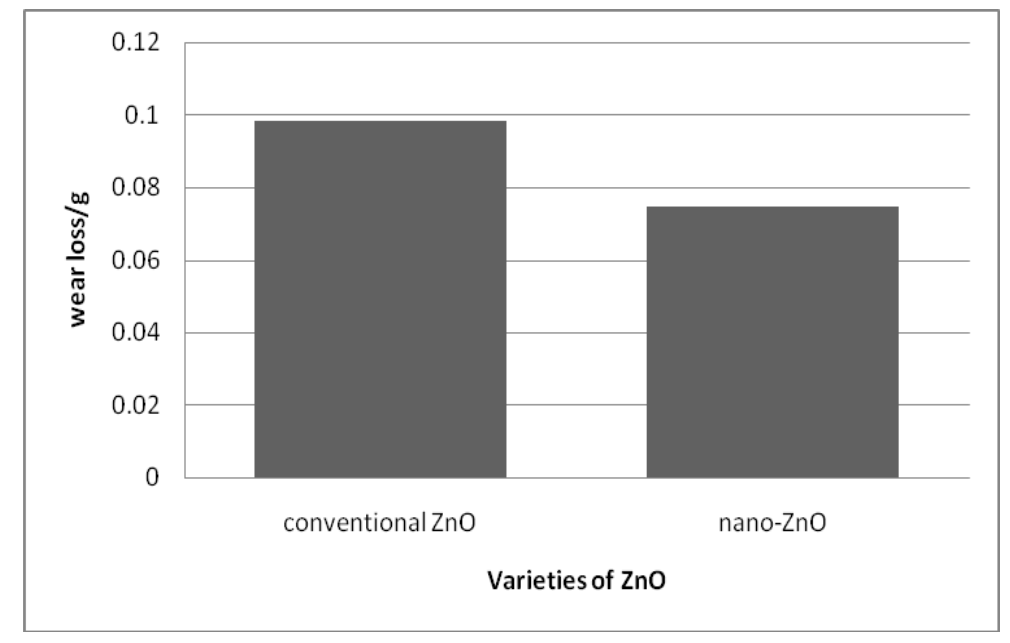

Fig.2 Variation of wear loss of NBR filled with different kinds of ZnO under dry sliding

Fig. 3 shows the morphologies of worn surface of rubbers with the load of $100 \mathrm{~N}$ under dry sliding. Obviously, apart from the plough, the worn surface shows the adhesion spot resulting from adhesion wear. The adhesion spots of NBR containing conventional $\mathrm{ZnO}$ are larger than that of NBR containing nano-ZnO, which showing that the adhesion wear resistance of NBR containing conventional $\mathrm{ZnO}$ is worse than that of NBR containing nano-ZnO. 

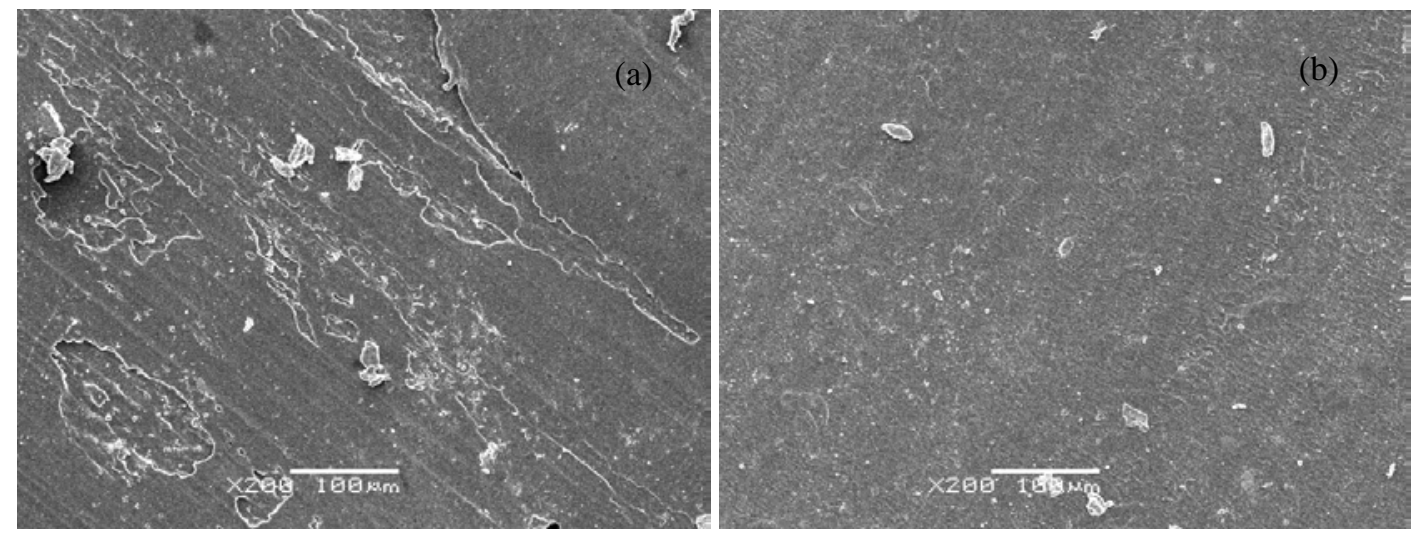

Fig.3 Morphologies of worn surface with the load of $100 \mathrm{~N}$ under dry sliding

(a) NBR containing conventional $\mathrm{ZnO}$ (b) NBR containing nano-ZnO

\section{Conclusions}

(1) Compared with NBR containing conventional $\mathrm{ZnO}$, the tensile strength of NBR containing nano-ZnO is enhanced by $9.6 \%$. The tensile stress at $100 \%$ and $300 \%$ is enhanced by $47 \%$ and $30 \%$, respectively. The NBR containing nano-Zno displays superior physical performances.

(2) The maximum torque of NBR filled with nano-ZnO is enhanced by $19 \%$, and the scorch time and optimum cure time is shortened by $13 \%$ and $23 \%$, respectively. These would be related to the activity of nano-ZnO.

(3) The frictional coefficient of both samples is basically steady with time. The wear mechanism should be single. The NBR containing nano-ZnO possesses less force of friction and frictional coefficient.

(4) The NBR containing nano-ZnO shows the more outstanding wear resistance, which is attributed to its higher crosslink density.

\section{References}

[1] Qingzhi Yang: Modern Technology of Rubber (China Petrochemical Press, Beijing 1997).

[2] Aibo Zhang, Jinpeng Xu and Yaping Zheng: China Rubber Industry, Vol.50 (2003), p.477-478

[3] Zhonglin Xie, Minfang Yang: Practical Formula of Rubber Products (Chemical Industry Press, Beijing 1993).

[4] Yuezhi Chen: Inner Mongolia Petrochemical Industry, Vol. 4(1998), p. 117

[5] Yuehui Chen, Jincheng Wang and Jihu Wang: China Rubber Industry, Vol.54 (2007), p. 17-20

[6] Zuowan Zhou, Longsheng Chu and Zaichang Zhang: China Rubber Industry, Vol.49 (2002), p.403

[7] Zhengxian Ma, Yuexin Han and Longxi Zheng: Chemical Industry and Engineering Progress, Vol.21 (2002), p. 60

[8] Zhe Wang, Shijie Wang and Hao Sun: Modular Machine Tool and Automatic Manufacturing Technique, Vol.9 (2010), p. 6-8

[9] Xiaoren Lv, Shijie Wang and Hao Sun: Lubrication Engineering, Vol.36 (2011), p. 63-66

[10] Hill D J T, Killeen M I and Donnell J H: Wear, Vol.208 (1997), p.155 160

[11] Leilei Wang, Xinmin Zhang: China Synthetic Rubber Industry, Vol.32 (2009),p.429-434

[12] Guiyi Wang: Special Purpose Rubber Products, Vol.21 (2000), p.55-61

[13] Bo Hu: Doctoral Dissertation on Qingdao University of Science and Technology (Qingdao University of Science and Technology, Qing Dao 2006).

[14] Stamhnis J E,Groenewoud W M and Madsen J. T: Plastics and Rubber Processing and Application,Vol.11 (1989),p. 93 98 